\title{
Structural and functional properties of pectin and lignin-carbohydrate complexes de-esterases: a review
}

\author{
Ayyappa Kumar Sista Kameshwar and Wensheng Qin*
}

\begin{abstract}
Biological conversion of plant biomass into commercially valuable products is one of the highly studied subjects in the last two decades. Studies were continuously being conducted to understand and develop efficient enzymes for the breakdown and conversion of plant cell-wall components into valuable commercial products. Naturally, plant cell-wall components are differentially esterified to protect from the invading microorganisms. However, during the process of evolution, microorganisms have developed special set of enzymes to de-esterify the plant cell-wall components. Among the carbohydrate-active enzymes (CAZy), carbohydrate esterases stand first during the process of enzymatic conversion of plant biomass, as these enzymes de-esterify the plant biomass and make it accessible for the hydrolytic enzymes such as cellulases, hemicellulases, ligninolytic and pectinases. In this article, we have extensively discussed about the structural and functional properties of pectin methyl esterases, feruloyl, cinnamoyl and glucuronoyl esterases which are required for the de-esterification of pectin and lignin-carbohydrate complexes. Pectin esterases are classified among CE8, CE12, CE13 and CE15 carbohydrate esterase class of CAZy database. Whereas, lignin-carbohydrate complex de-esterifying enzymes are classified among CE1 (feruloyl esterase) and CE15 (glucuronoyl esterase) classes. Understanding the structural and functional abilities of pectin and lignin-carbohydrate esterases will significantly aid in developing efficient class of de-esterases for reducing the recalcitrant nature of plant biomass. These efficient de-esterases will have various applications including pretreatment of plant biomass, food, beverage, pulp and paper, textile, pharmaceutical and biofuel industries.
\end{abstract}

Keywords: Pectin, Lignin-carbohydrate complexes, Pectin methyl esterase, Feruloyl esterase, Cinnamoyl esterase, Glucuronoyl esterase

\section{Background}

Pectin is a natural heterogenous polysaccharide present in plant cell walls especially between the middle lamella, occurring as calcium and magnesium salts. Plant physiological studies based on the uptake of ruthenium red and alkaline hydroxylamine stains (Albersheim and Killias 1963; Gee et al. 1959; McCready and Reeve 1955; Sterling 1970) have confirmed that pectic substances majorly occur in the middle lamella of the plant cell wall. The composition of pectin in plant cell walls varies based on the type of plants, e.g., dicotyledonous plant cells contain

*Correspondence: wqin@lakeheadu.ca

Department of Biology, Lakehead University, 955 Oliver Road, Thunder Bay, ON P7B 5E1, Canada
$35 \%$ of pectin, grasses contain $2-10 \%$ and in woody tissue $5 \%$ (Voragen et al. 2009). The exact molecular weight of pectic substances is not well defined compared to other plant cell-wall components. However, studies have reported that the relative molecular weight of pectic substances ranges between 25 and $300 \mathrm{kDa}$, e.g., apple and lemon-200-360 kDa, pear and prune-25-35 kDa, orange-40-50 kDa and sugar beet pulp-40-50 kDa (Jayani et al. 2005). Naturally, pectic substances occur in galacturonans and rhamnogalacturonans-I and -II. These pectic substances contain anhydrogalacturonic acid backbone, where carboxyl groups are partially esterified by $O$-acetyl and methyl groups with the hydroxyl groups present on the $\mathrm{C}-2$ and -3 positions (Table 1). Pectin contains long chains of $\alpha$-D-galacturonate units joined by 
Table 1 Structural properties and occurrence of different 0 -acetylated pectin structures reported below were retrieved from (Pawar et al. 2013)

\begin{tabular}{|c|c|}
\hline Acetylated forms of polysaccharides & Properties and occurrence \\
\hline Rhamnogalacturonan I & $\begin{array}{l}\text { Rhamnogalacturonan I, a group of structurally complex pectic polysaccharides. With a repeat- } \\
\text { ing backbone composed of diglycosyl }[\rightarrow 2)-a-L-R h a p-(1 \rightarrow 4)-a-D-G a l p A-(1 \rightarrow] \text {, branched at } \\
\text { O-4/O-3 positions by four different side chain types: }(1 \rightarrow 5)-\text {-L-arabinan, }(1 \rightarrow 4)-\beta \text {-D-galactan, } \\
\text { arabinogalactan-l, and sometimes with arabinogalactan-II (Pawar et al. } 2013 \text {; Yapo 2011). It is } \\
\text { present in primary cell walls of soft and hardwoods (Pawar et al. 2013) }\end{array}$ \\
\hline
\end{tabular}

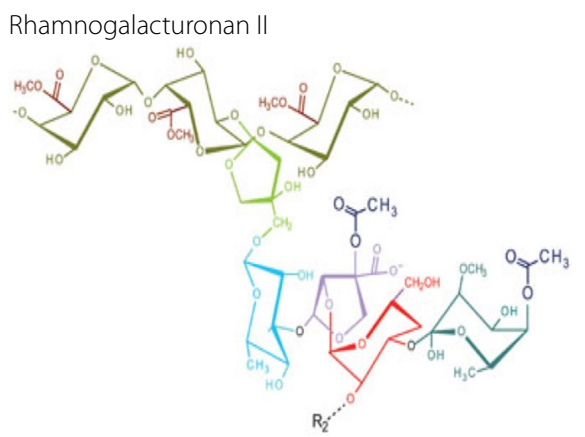

Rhamnogalacturonan II is a low-molecular weight pectic polysaccharide with 5-10 kDa released upon treatment with endo-a-1,4-polygalacturonases. Structurally, rhamnogalacturonan II is a homogalacturonan backbone containing at least 7-9 residues containing five oligosaccharide side chains such as A-E [as described in Pérez et al. (2003)]. Naturally, rhamnogalacturonan II was found to occur in primary cell walls of soft and hard wood, also in cell walls of growing plant cell walls (Pérez et al. 2003)

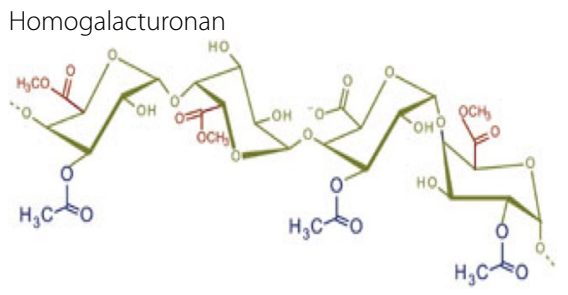

Homogalacturonan is one of the major constituents of the pectic polysaccharides. Structurally, it contains long chains of D-galacturonic acid units linked through $\mathrm{a}-(1 \rightarrow 4)$ bonds, which are methyl or acetyl esterified at C-6 position with acetyl/methyl group on 0-2 or O-3 positions. It is synthesized from the nucleotide sugars in the Golgi apparatus and are then transported to cell wall in fully methylesterified forms (Sénéchal et al. 2014)

$\alpha(1 \rightarrow 4)$ linkages and $2-3 \%$ of L-rhamnose units were found in association with the galacturonate units joined through $\beta(1 \rightarrow 2)$ and $(1 \rightarrow 4)$ linkages forming the primary chain of pectic substances. The American chemical society has classified the pectic substances into four different types as (a) protopectin, (b) pectic acid, (c) pectinic acid and (d) pectin. Thus, degradation of these pectin structural variants requires different pectinolytic enzymes, which can be broadly classified into three main classes (a) protopectinases (b) esterases and (c) depolymerases (Table 2).

Naturally, most of the fungi, bacteria and yeast secrete wide range of pectin methyl esterases and pectindepolymerizing enzymes for the degradation of pectin. Previous studies have extensively reported about various endogenous pectinases secreted by plants (Sakai and Okushima 1982; Sakai et al. 1993; Sakamoto et al. 1994; Whitaker 1990). Based on their specific location of activity, protopectinases were classified as A-type (inner site/reacts at the polygalacturonic acid region) and B-type (outer site/polysaccharide chains connected to polygalacturonic acid chain). A-type protopectinases were majorly reported to be secreted in the cultures of yeast and yeast like fungi, whereas B-type proto-pectinases were majorly reported in the cultures of Bacillus strains and especially in Bacillus subtilis cultures (Sakai and Okushima 1982; Sakai et al. 1993; Sakamoto et al. 1994). Polygalacturonases are class of pectinolytic enzymes which performs the hydrolytic cleavage of polygalacturonic acid by introducing water across the oxygen bridge. Based on its reactivity, polygalacturonases are divided into endo- (widely reported among fungi, bacteria and yeast, and were also reported in higher plants and parasitic nematodes) (De Lorenzo et al. 1987; Luh and Phaff 1951; Manachini et al. 1987; Marcus et al. 1986; Maria de Lourdes et al. 1991; Sakai et al. 1984) and exo-polygalacturonases (well studied in Erwinia carotovora, Agrobacterium tumefaciens, Bacteroides thetaiotaomicron, E. chrysanthemi, Alternaria mali, Fusarium oxysporum, Ralstonia solanacearum, 
Table 2 Different types of pectic substances and pectinolytic enzymes responsible for its degradation
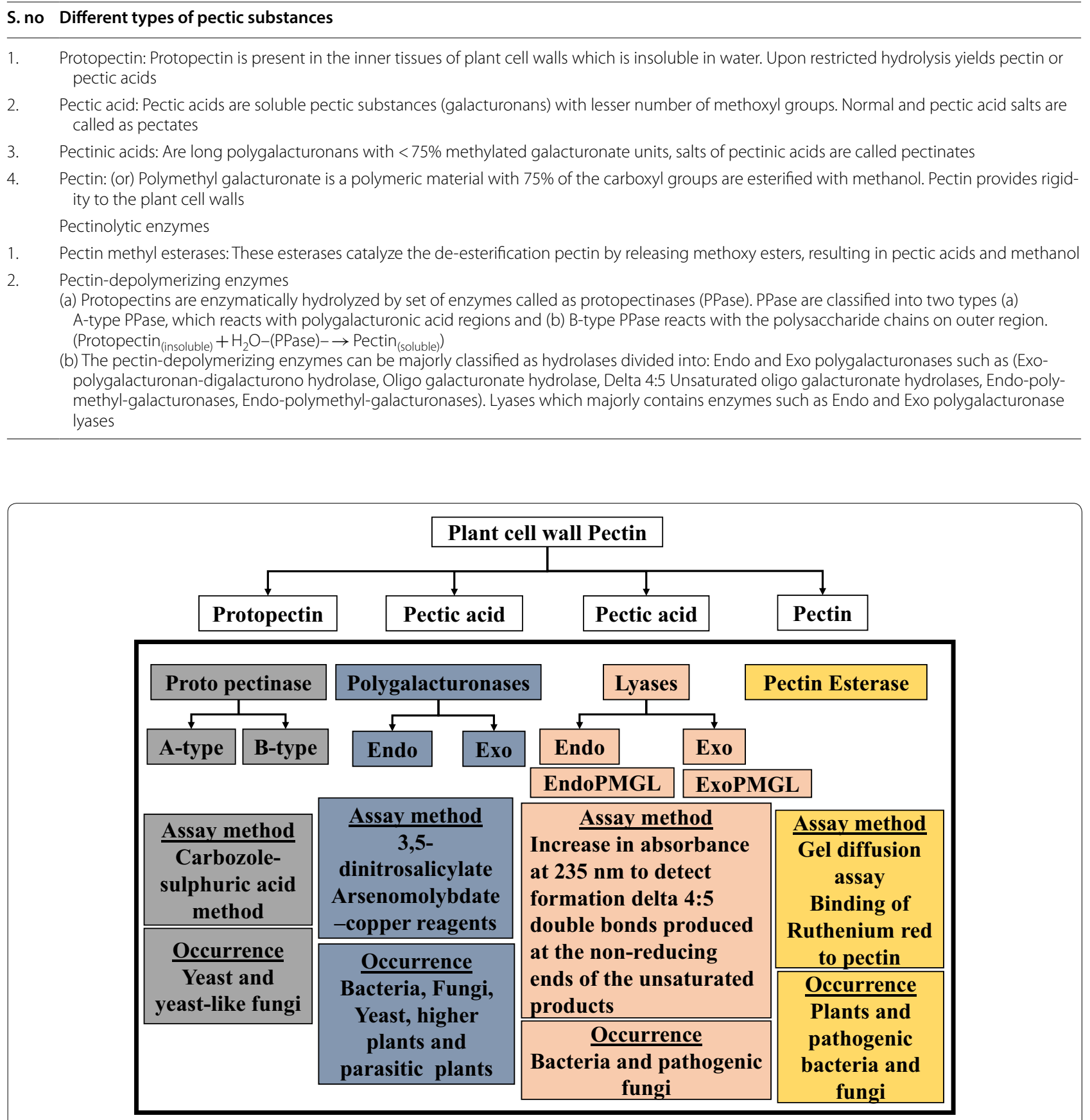

Fig. 1 Brief illustration of different pectin-degrading enzymes, its occurrence and assay methods used for its characterization

Bacillus sp) (Garcıća Maceira et al. 1997; Kobayashi et al. 2001; Nozaki et al. 1997; Reymond et al. 1994; Rodriguez-Palenzuela et al. 1991; Tierny et al. 1994). Pectin lyases catalyze non-hydrolytic cleavage of pectates or pectinates, lyases cleaves the glycosidic linkages at $\mathrm{C}-4$ by simultaneously eliminating the $\mathrm{H}$ at $\mathrm{C}-5$ by producing 4:5 double-bonded unsaturated products.
Polygalacturonate lyases were majorly reported to be secreted by bacteria and some pathogenic fungi, especially soft rot fungi (Fig. 1). Pectin esterases are a class of carbohydrate esterases which are involved in deesterification of methyl ester linkages present on the galacturonan chains of pectic substances present in the plant cell wall (Cosgrove 1997; Micheli 2001; Prade 
et al. 1999; Whitaker 1984). The de-esterified pectin is further degraded by the polygalacturonases and lyases (Fig. 1) (Prade et al. 1999; Sakai et al. 1993). The mode of action of the pectin esterases differs significantly based on its origin; pectin esterases secreted by fungi act through a multichain mechanism to cleave methyl groups randomly. Whereas, pectin methyl esterases originated from plant act either on the non-reducing ends or on the groups next to free carboxyl groups by a single chain mechanism (Förster 1988; Micheli 2001).

Lignin, the heterophenolic polymer present in the plant cell wall, is considered as the major drawback in the production of bioethanol. Naturally, lignin is found to occur in intricate networks with plant cell-wall carbohydrates. Lignin forms ester linkages through its alcohols with hemicellulose through 4-O-methyl-D-glucuronic acid side residues of glucuronoxylans (Pokkuluri et al. 2011). According to Del Río et al. (2007) similar to pectin and hemicellulose, lignin present in plant cell walls, was also found to be acetylated on the aliphatic side chains (gamma carbon) of lignin S and G monomers (Del Río et al. 2007). Studies have reported that extraaxillary fibers in jute, abaca and kenaf exhibit highest degree of acetylation with degree of acetylation up to 0.8 and lignin acetylation in hardwood xylem varies between 1 and 50\% (w/w). However, studies need to be conducted to determine the degree of acetylation in softwood xylem and the reasons behind the variation of lignin acetylation in plants (Del Río et al. 2007; Pawar et al. 2013). Ferulic acid is a most abundant phytochemical phenolic compound derived from cinnamic acid 3-(4-hydroxy-3-methoxyphenyl-2-proponoic acid), 4-hydroxy-3-methoxycinnamic acid, or coniferic acid (Fazary and JU 2007). Ferulic acid is commercially an important compound and it is widely distributed in the whole plant kingdom, it is highly studied for its anti-oxidant properties (Fazary and JU 2007). However, in the nature, ferulic acid occurs in its esterified form which is covalently connected to the lignin, glycoproteins, and to the insoluble carbohydrate components mono- and di-saccharides of the plant cell-wall components (Fazary and JU 2007; Kroon et al. 1997). The feruloyl esterases attack and convert ferulic acid and cinnamic acid present in the plant biomass; because of this ability, feruloyl or cinnamoyl esterases have gained higher industrial importance (Benoit et al. 2008).

\section{Carbohydrate esterases de-acetylating pectin}

Enzymes required for the breakdown of pectin can be majorly classified into three categories as protopectinases (involved in breaking insoluble protopectin and results in soluble polymerized pectin), depolymerizing enzymes (required for breaking down $\alpha(1 \rightarrow 4)$ glycosidic linkages of pectin) and esterases (required for the de-esterification and de-acetylation of pectin) (Gonzalez and Rosso
2011). Pectinolytic enzymes are widely observed among plants, bacterial and fungal species and most of the pectin methyl esterases can be divided based on their optimum $\mathrm{pH}$; bacteria and plant $\mathrm{PME}$ exhibit an optimum $\mathrm{pH}$ range between 6 and 8 and PME secreted by fungi exhibit a pH 4-6 (Gonzalez and Rosso 2011; Jayani et al. 2005). Pectin-degrading enzymes have attained high commercial importance since early 1930s in wine and fruit juice industries; pectinolytic enzymes secreted by Aspergillus species are highly used in industries (Alkorta et al. 1998). Pectin present in vegetable tissues and majorly in fruits contains complex hetero polysaccharides at a molecular weight ranging between 25 and $360 \mathrm{kDa}$. Calcium and magnesium pectate forms the major constituent of the plant cell walls especially in middle lamella (Jayani et al. 2005). The gelling property of pectin majorly employed in the food industries is directly dependent on its degree of esterification; pectins with higher degree of esterification gel around $\mathrm{pH} 3.0$ in the presence of sugar, whereas pectins with low degree of esterification gel in the presence of calcium ions under wide $\mathrm{pH}$ ranges and with or without sugar (Fu and Rao 1999, 2001; Gonzalez and Rosso 2011).

Pectin methyl esterases or alkaline reagents were majorly used to demethoxylate large galacturonic chain for reducing the overall pectin methoxylation content (Gonzalez and Rosso 2011). Majorly, pectinolytic enzymes were highly applied in fruit juice and wine industries for the clarification of the fruit juices, modification of fruits and vegetables (Kohli et al. 2015). Apart from these applications, pectinolytic enzymes were also used for extracting oils from germ, palm, coconut, sunflower seed and kernel rape seeds, by replacing the conventionally used carcinogenic solvents like hexane. These pectinolytic enzymes extract oil from different crops by liquefying the structural components of the cell walls. Commercial pectinase preparations called Olivex ${ }^{\circledR}$ were applied in olive oil industries for the extraction of oil and to increase the quality (Kashyap et al. 2001; Vierhuis et al. 2003). Rhamnogalacturonan, a complex polysaccharide unit present in the primary cell walls and middle lamella of higher plants, with alternating rhamnose and galacturonic acid residues acetylated majorly at C-2 and C-3 positions (Ishii 1997). As the acetylation of these residues sterically hinders the catalytic function of the corresponding lyases and hydrolases on the glycosidic linkages, deacetylation facilitates the action of the lyases and hydrolases. Thus, rhamnogalacturonan acetyl esterase belonging to CE-12 family has gained significance in deacetylation of these residues and also been used industrially for the production of $\beta$-lactam antibiotics and paper bleaching purposes (NavarroFernández et al. 2008). We have specifically reviewed the structural and functional properties of pectin methyl and acetyl esterases below (Table 3). 
Table 3 List of the structural and functional properties of pectin-deacetylating esterases belonging to CE-8 and CE-12 of carbohydrate esterases

\begin{tabular}{llll}
\hline Strain, PDB ID, CE class & $\begin{array}{l}\text { Catalytic residues } \\
\text { and reaction type }\end{array}$ & CATH and Pfam & $\begin{array}{l}\text { Enzyme and fold } \\
\text { Substrates and Refs }\end{array}$ \\
\hline Erwinia chrysanthemi, [1QJV], CE-8 & $\begin{array}{l}\text { Asp178, Asp199, Arg267 } \\
\text { Aspartic esterase }\end{array}$ & $\begin{array}{l}\text { 3-Solenoid } \\
\text { Pectinase lyase C-like pectinesterase }\end{array}$ & $\begin{array}{l}\text { Pectin methyl esterase, single stranded right- } \\
\text { handed } \beta \text {-helix, pectin present in cell wall } \\
\text { polysaccharides is hydrolyzed to pectate and } \\
\text { methanol (Jenkins et al. 2001) }\end{array}$ \\
Aspergillus aculeatus, [1DEX], CE-12 & $\begin{array}{l}\text { Ser9, His195, Asp192 } \\
\text { Serine esterases }\end{array}$ & $\begin{array}{l}\text { 3-Layer a/ } \beta \text { sandwich } \\
\text { Rossmann fold } \\
\text { GDSL-like lipase/acylhydrolase }\end{array}$ & $\begin{array}{l}\text { Rhamnogalacturonan acetylesterase flavodoxin- } \\
\text { like (SGNH hydrolase). Rhamnogalacturonan } \\
\text { present in the cell walls. RGAE functions in } \\
\text { coordination with rhamnogalacturonan lyases } \\
\text { and hydrolases (Mølgaard et al. 2000) }\end{array}$ \\
& & & \\
\hline
\end{tabular}

The structural and functional properties such as SCOPE and CATH related information was retrieved from RCSB PDB data repository, appropriate references and the corresponding PDB ID's were reported in the table

Several studies were conducted in the past to understand the structural and functional properties of pectinolytic enzymes. Present day, National Center for Biotechnological Information (NCBI) repositories resides about 20,933 reports on pectin esterases which can be majorly classified as 1758 (NCBI Literature), 15 (NCBI Health), 3503 (NCBI Genomes), 15,230 (NCBI Genes), 395 (NCBI Proteins) and 42 (NCBI Chemicals). Till date, there are 189 protein sequences, 160 protein clusters (expressing seven conserved domains related to pectin esterases) and 30 experimentally-determined biomolecular structures of pectin methyl esterases available in NCBI and PDB (protein data bank) repositories respectively. The protein data bank (PDB) contains structures of 3-pectin methyl esterases of bacteria (Dickeya dadantii, Yersinia enterocolitica, Dickeya chrysanthemi) and one fungal pectin methyl esterase of Aspergillus niger and four pectin methyl esterases of plants (Arabidopsis thaliana, Solanum lycopersicum, Daucus carota, Sitophilus oryzae, Actinidia chinensis). In this article, we have extensively focused on understanding the structural and functional properties of pectin methyl esterases of microorganisms.

\section{Erwinia chrysanthemi (CE class-8)}

Jenkins et al. (2001), for the first time, have studied and revealed the $3 \mathrm{D}$ structure of pectin methyl esterase isolated from Erwinia chrysanthemi refined at $2.4 \AA$, where it contains two identical molecules with 342 amino acid residues in the crystallographic asymmetric unit (Jenkins et al. 2001). Pectin methyl esterase (pemA) is a righthanded parallel $\beta$-helix structure resembling other pectin and pectate lyase, by having same number of total coils. Each parallel $\beta$-helix turn further contains three $\beta$-strands PB1, PB2 and PB3 which are in turn connected through loops called as T1 (connecting PB1 and PB2), T2 (PB2 to PB3) and T3 (PB3 to PB1) of another coil. It also contains a $\alpha$-helix at the end of $\mathrm{N}$-terminal of parallel $\beta$-helix; long T3 loops and $\mathrm{T} 1$ loops are arranged near $\mathrm{C}$-terminal end of parallel $\beta$-helix. The occurrence of $\alpha$-helix allows the existing structures of the pectinolytic enzymes to align structurally, so that half of the $\alpha$-carbon atoms are arranged approximately at $2 \AA$. Loop conformations extended from the pemA parallel $\beta$-helix were not comparable to that of other pectinolytic enzymes even at the position of $\mathrm{T} 3$ loops in space, as they might come from different coils. The $\beta$-structure formed from two long T1 loops are internally hydrogen bonded, and the $\beta$-hairpins and the hydrogen bond present in between the hairpins give a suggestion of the anti-parallel four strand sheet. Aminoacid residues from 342 to 359 of parallel $\beta$-helix are involved in the formation of one distorted $\alpha$-helix (342-359) or two distorted $\alpha$-helix (342-352 and 353-359) containing Tyr242 and Thr353 residues, where the side chains of these residues interact with 351-O and 356- $\mathrm{N}$ residues through the hydrogen bonds, forming an antiparallel structure against parallel $\beta$-helix as the $\mathrm{C}$-terminal of $\alpha$-helix of lyases.

Unlike the conserved $C$-terminal extension and $\alpha$-helix of rhamnogalacturonase A (RGase A) arranged against PB3, aminoacid residues from 345 to 359 are packed against PB2, which further interact with equivalent residues in pectate lyases forming an extended chain reaching to the conserved $\alpha$-helix against PB3. Structurally, several lipases and esterases exhibited a common $\alpha / \beta$ hydrolase fold with a catalytic Ser-His-Asp triad. But pectin methylesterases showed some variation with respect to the protein structure and catalytic triad location. Interestingly, sequence alignments of pectin methylesterases does not show any conserved histidine and serine residues but show various other conserved aminoacid residues. The conserved aminoacid residues mapped against the structure of the pemA shows a different cluster with a deep cleft on the surface of the enzyme. The cleft present on the surface of the enzyme is involved in substrate binding and active site formation, by containing several aromatic residues. 
The active site region was found to contain three conserved aminoacid residues Asp178, Asp199 and Arg267. According to Jenkins et al. (2001), these two conserved aspartate residues and their adjacent arginine residue are considered as the catalytic residues, as there is no other substantial candidate to be determined as catalytic sites (Jenkins et al. 2001). The aspartate residues are equally arranged on the neighboring coils, thus having same lefthanded $\alpha$-helices. The Asp199 was found to be in close contact with Arg267 which partially blocks Asp199 from the solvent and forms hydrogen bonds with NE and NH1 of the side chain oxygen atoms (Jenkins et al. 2001). The second aspartate residue Asp178 interacts with two water molecules which shields it form interacting with the solvent molecule from glutamine residues (Gln153 and Gln177) and with the $\beta$-carbon atom of Asp199 residue. The aromatic residues Tyr158, Tyr181 and Phe202 on the exposed surface of PB1 forms a floor of valley at Tyr269 of a T1 loop. With the Tyr181, Phe202 and Trp269 residues are found to be conserved in most pectin methylesterases sequences. Fries et al. (2007) have performed site-directed mutagenesis of the pectin methylesterase (E. chrysanthemi) to understand the functional properties of aminoacid residues in catalytic site (Fries et al. 2007). This study has also reported that following residues Asp199, Asp178, Gln177 are involved in reaction mechanism, though Arg267 was found to be conserved among all the pectin methyl esterases and is not directly involved in enzyme catalysis (Fries et al. 2007). The $E$. chrysanthemi pemA was found to be active between $\mathrm{pH}$ 5 and 9; however, at $\mathrm{pH} 5$ pemA showed highest activity (Pitkänen et al. 1992). The catalytic Asp178 residue might mostly be found in its protonated state due to its position in a hydrophobic environment, while the Asp199 occurs in deprotonated at neutral $\mathrm{pH}$ as it is accessible by the solvents. The negative charge and the position of Asp199 are favored by hydrophobic residues Arg267, Ala233, Tyr230 and Val198 and direct Asp199 towards incoming substrate and solvent. The presence of hydrogen bonds between the Arg267 and Asp199 oxygen atom assists in maintaining the Asp199 residues deprotonated state. The two glutamine residues Gln153 and Gln177 present near the Asp199 and Asp178 residues might contribute to the oxyanion hole (Fries et al. 2007; Johansson et al. 2002).

These crystallographic studies have provided clear insights on the reaction mechanism of pectin methyl esterase at atomic resolution (Fries et al. 2007; Jenkins et al. 2001). The Asp199 acts as nucleophile, as it directly attacks the carbonyl carbon of methyl ester, with Asp178 acting as general acid-base in the reaction. Lack of water molecule between Asp199 and substrate rules out the earlier proposed mechanism (reaction is initiated by activating the water molecule). The reaction proceeds through simple activation of methyl ester by Asp178 by avoiding the nucleophilic assistance of Asp199, which might question the conservation of Asp199 residue and its stereochemical chemistry at the catalytic site across the pectin methyl ester family. Though Arg267 and Trp269 residues are not directly involved in catalytic reaction, they are required for the substrate binding. The hydrolytic water molecule which is involved in hydrolysis of the acyl enzyme is observed during the low $\mathrm{pH}$ and time course adjacent to the Asp178 (general base). This protein structure also suggests that Gln 177 is involved in the formation of oxyanion hole and the kinetic analysis proves the role of Gln177 in stabilization of transition state; similarly, Gln153 is required for substrate binding (Fries et al. 2007; Jenkins et al. 2001) (Fig. 2).

\section{Aspergillus aculeatus (Rhamnogalacturonan acetylesterase CE class-12)}

The three-dimensional structure of the rhamnogalacturonan acetylesterase (RGAE) from Aspergillus aculeatus was revealed by (Mølgaard et al. 2000). Protein structure of RGAE was determined by multiple isomorphous replacement and refined at $1.55 \AA$ resolution (Mølgaard et al. 2000). The protein structure of RGAE exhibited a $\alpha / \beta / \alpha$ fold containing a central five-stranded parallel $\beta$-sheet surrounded by $\alpha$-helices, with a structural topology of central sheet to be found as $-1 \mathrm{X} 2 \mathrm{X} 1 \mathrm{X} 1 \mathrm{X}$ with two stranded antiparallel $\beta$-sheet insertion after the third $\beta$-strand. There are total of 11 helices in the protein structure containing four $3_{10}$ helices (A, B, E and K). Due to the lack of backbone hydrogen bonds between Glu25Ala28 and Tyr26-Ser29, A and B are assigned as two separate helices. There are two disulfide bridges formed by four cysteine residues, which are involved in linking the aminoacid residues 88-96, 214-232 with other disulfide bridges anchoring the $\mathrm{C}$-terminal loop and $\alpha$-helix. Though, electron density maps do not show any indication of $\mathrm{O}$-glycosylation sites, but it showed two $\mathrm{N}$-glycosylation sites (Asn104 and Asn182) which allows a total of seven carbohydrate residues in the electron density map (Mølgaard et al. 2000).

The active site inferred from the 3D structure of RAGE shows that Ser9 residue present on the topological point at the end of $\beta$-strand is involved in forming the characteristic hydrogen bonds in the catalytic triad with His195 and Asp192. The electron density maps showed that the sulfite ion is bound to the active site of the RGAE protein with oxygen atom occupying the oxyanion hole through making hydrogen bonds with main chain $\mathrm{NH}$ groups of Ser9, Gly 42 and side chain amide of Asn74, which are located in the loop regions next to carboxy ends of first three strands in central $\beta$-sheet (Mølgaard et al. 2000). The second sulfate oxygen atom is hydrogen bonded with 


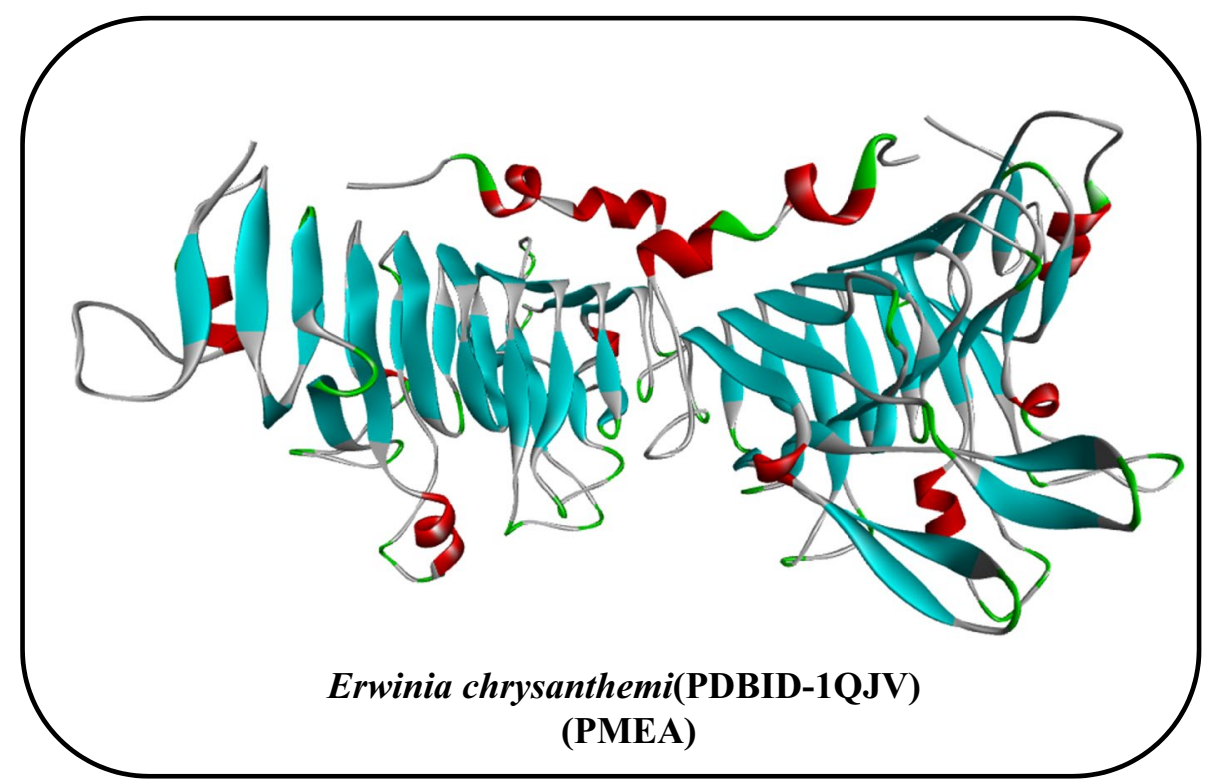

Fig. 2 The protein secondary structure of Erwinia chrysanthemi pectin methyl esterase (carbohydrate esterase class-8) (PDB ID:1QJV) (Jenkins et al. 2001), where alpha-helices (red), beta strands (blue) and coils (gray). (Image was developed using Discovery Studio Visualizer ${ }^{\circledR}$ )

the imidazole group of His195, thus connecting four different regions of the protein structure. These structural studies have extensively revealed the structural localization of catalytic triad residues. The Ser9 residue which acts as nucleophile is present in the type-I $\beta$ turn, Asp192 and His195 are arranged in loop region which connects the two helices near the C-terminal end. The position of the active site makes it accessible for a wide range of large substrates, as it is situated in the bottom of the open cleft. Most of the arginine residues are situated in suitable positions for its interactions with the negatively charged carboxylate groups of the substrates (Mølgaard et al. 2000).

The $\alpha / \beta$ hydrolase fold adopted by most of the neutral lipases and esterases consists of a central parallel $\beta$-sheet (eight stranded) surrounded by $\alpha$-helices (Ollis et al. 1992). Majorly, the catalytic triad residues from the $\alpha / \beta$ hydrolases follow an order of nucleophile-acid-histidine and in most of the protein structures, the topology and the positions of these residues are similar. The nucleophile is situated at the end of 5 th $\beta$-strand, acid is located at the end of 7 th $\beta$-strand and the histidine follows the loop region of 8th strand; thus, $\alpha / \beta$ hydrolase fold characteristic motif is also called as nucleophilic elbow (Derewenda and Derewenda 1991; Ollis et al. 1992). This nucleophile backbone attains a strained $\varepsilon$ conformation due to situation of nucleophile in a sharp turn between a $\beta$-strand and $\alpha$-helix, the small helix (Sm) any residue (X) and nucleophile $(\mathrm{Nu})$ residues are arranged specifically as $\mathrm{Sm}-\mathrm{X}-\mathrm{Nu}-\mathrm{X}-\mathrm{Sm}-\mathrm{Sm}$ for forming a motif. However, the protein structure of RGAE violates this consensus sequence as large side chains of methionine (Met11) located at $\mathrm{Nu}^{2+}$ position making it sterically impossible to form a sharp turn which is mandatory for nucleophile elbow motif. Secondly, the most conserved $\alpha$-helix $C$ present in $\alpha / \beta$ hydrolases is not conserved in the protein structure of RGAE (Schrag and Cygler 1997). The 3D structure of RGAE also revealed that nucleophile backbone conformation is unstrained, as it is situated on typeI $\beta$ turn following a loop region. Although RGAE follows similar sequential order of catalytic residues (Ser-AspHis) as $\alpha / \beta$ hydrolase fold, they differ in their location. In $\alpha / \beta$ hydrolases, the Asp and His are located quite far from each other in sequence; whereas, in RGAE they are only separated by two residues. RGAE differs from $\alpha / \beta$ hydrolases with respect to the orientation of the catalytic residues and the remaining protein structure. The catalytic triad residues in $\alpha / \beta$ hydrolases are arranged parallel to the central $\beta$-sheet; whereas in RGAE, these residues are arranged perpendicularly to the central $\beta$-sheet. However, these differences do not severely affect the catalytic functions of the nucleophile on carbonyl carbon or the enzyme (Mølgaard et al. 2000) (Fig. 3; Table 3).

\section{Carbohydrate esterases for de-esterification of lignin- carbohydrate complexes}

Plants contain a range of hydroxycinnamic acids like caffeic, $p$-coumaric, ferulic and sinapic acids which can be broadly classified as phenolic compounds and highly abundant among foods (Guglielmetti et al. 2008). 


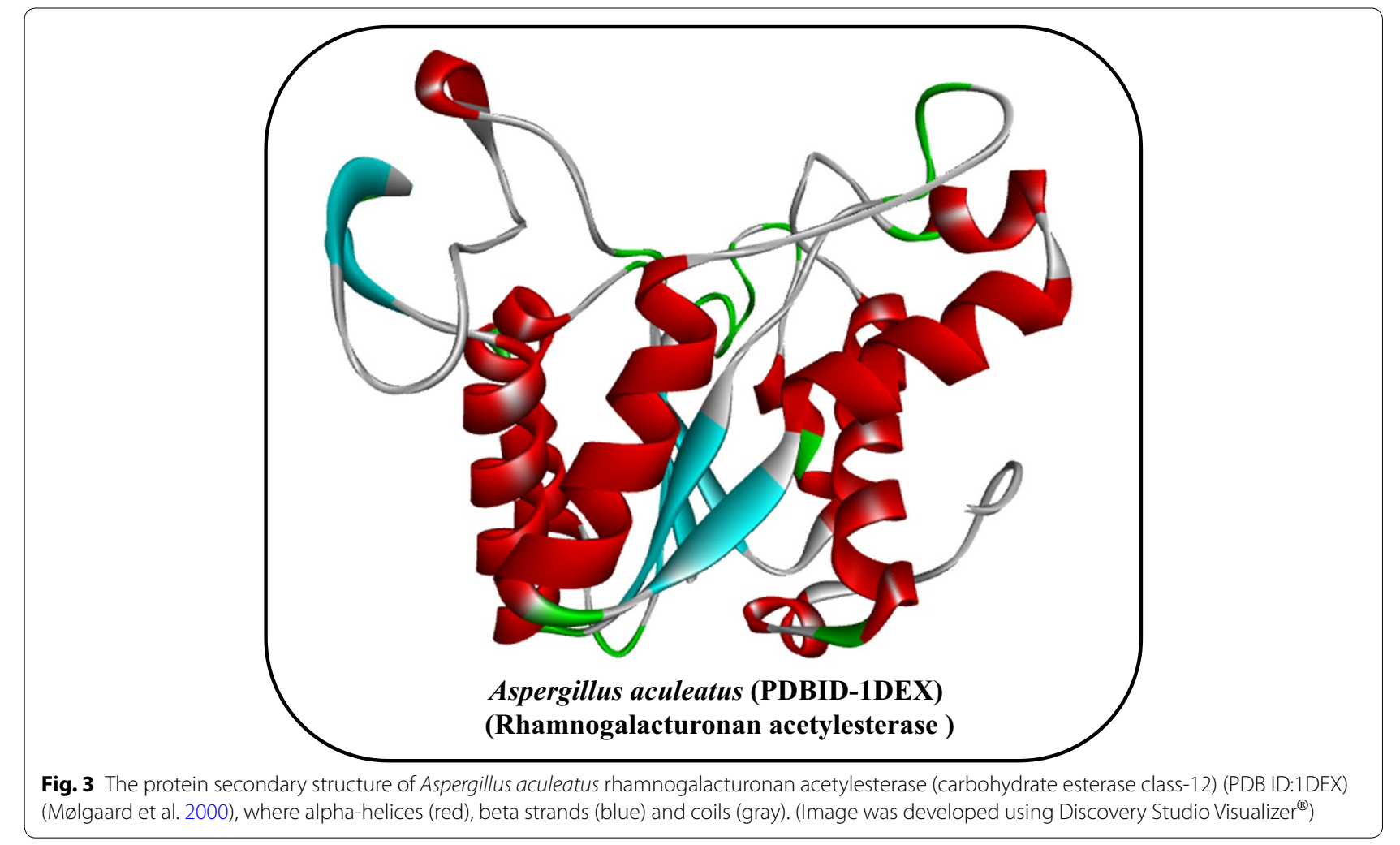

Feruloyl esterases (or ferulic acid esterases) or cinnamoyl esterases are carbohydrate esterase class of enzymes which hydrolyze the ester linkages between hydroxycinnamic acids and plant cell-wall carbohydrates by releasing ferulic and cinnamic acid (Topakas et al. 2007). Combinatorial usage of feruloyl esterase or cinnamoyl esterases with glycoside hydrolases for the liberation of free carbohydrate residues and phenolic acids can significantly aid in different preprocessing steps of biofuel and biorefining industries (Faulds 2010). The activity of FAE and CAE are chiefly limited to the position and conformations of the feruloyl groups present in the feruloylated polysaccharides and other surrounding cell-wall components. Recent studies conducted by Faulds et al. (2003, 2006) have revealed the preferential partnership between glycoside hydrolase class-11 (GH-11) xylanases and FAE for liberating ferulic acid from the insoluble biomass, while partnership between $\mathrm{GH}-10$ xylanases and FAE will liberate 5,5'dimers (Faulds et al. 2003, 2006). Glucuronoyl esterases are the class of carbohydrate esterases involved in hydrolysis of the ester linkages present between 4-O-methyl-D-glucuronic acid residues of glucuronoxylans and aromatic alcohols of lignin (Špániková and Biely 2006). Glucuronoyl esterase which is involved in plant cell-wall degradation was discovered in Schizophyllum commune for the first time (Špániková and Biely 2006). Duranová et al. (2009) have purified and characterized the fungal glucuronoyl esterase using a series of uronic acids and their glycoside derivatives (Duranová et al. 2009). These studies have revealed the specificity of GE towards 4-O-methyl-D-glucuronic acid, its methyl esters and D-glucuronic acid containing 4-nitrophenyl aglycon, showing that GE attack the ester bonds between 4-O-methyl-D-glucuronic acid of glucuronoxylan and alcohols of lignin (Ďuranová et al. 2009; Topakas et al. 2010). Glucuronoyl esterase finds its applications in growing biofuel and biorefinery industries as it breaks down and separates the hemicellulose and lignin.

Pretreatment step is currently being used in bioethanol industries for releasing free carbohydrate residues from the other aromatic components of the cell wall. The heterophenolic lignin compounds interacting with the polysaccharide units increase the recalcitrant nature of the plant cell wall and the percentage of lignin in plant tissues is directly proportional to its digestibility. It has been assumed that FAEs and CAEs are required for breaking the lignin and carbohydrate linkages. According to Benoit et al. (2006), type-C and type-B FAEs isolated from $A$. niger release higher proportions of ferulic acid and $p$-coumaric acid from the steam-exploded wheat straw (Benoit et al. 2006). The type-A FAE from $A$. niger was found to be effective against the steam-exploded wheat straw in the presence of cellulases and xylanases, and at $50{ }^{\circ} \mathrm{C}$ the rate hydrolysis increased significantly (Tabka 
et al. 2006). Similarly, Selig et al. (2008) have used a combination of cellobiohydrolase Cel7A, xylanase, feruloyl esterase and acetyl xylan esterase and reported enhanced breakdown of the hot water-treated corn stover cellulose (Selig et al. 2008). Apart from its long list of applications, FAEs were also used for the utilization of straws in paper industries (Record et al. 2003; Tapin et al. 2006), detoxification of animal feed (Laszlo et al. 2006), for the removal of cinnamic acids and $p$-coumaric acids from coffee pulp (Benoit et al. 2006). Thus, wide applications of FAE and CAE in food, paper and pulp, biofuel industries make these enzymes economically and commercially important enzymes (Table 4).

\section{Lactobacillus johnsonii (Cinnamoyl esterase CE class I)}

The three-dimensional structures of native and mutant cinnamoyl esterase secreted by Lactobacillus johnsonii was revealed by (Lai et al. 2011). The native apo cinnamoyl esterase (3PF8) structure consists of central $\beta$-sheet containing seven parallel $\beta$-strands $(\beta 1, \beta 3, \beta 4$, $\beta 5, \beta 6, \beta 11, \beta 12)$ and one anti-parallel $\beta$-strand $(\beta 2)$. The central $\beta$-sheet exhibits a superhelical twist with $120{ }^{\circ} \mathrm{C}$ angle from $\beta 1$ to $\beta 2$ strands, central $\beta$-strand is edged by five $\alpha$-helices where two $\alpha$-helices are located externally ( $\alpha 1$ and $\alpha 9)$ and three $\alpha$-helices are internally located ( $\alpha 3, \alpha 4$ and $\alpha 8)$ near the dimer interface. Two protein molecules of the 3PF 8 are involved in extensive interface formation which consists of $\alpha 4, \alpha 6$ and $\beta 1$ strand. Lai et al. (2011) have also reported the protein interactions and surface assemblies analysis (PISA server); based on these results, it was revealed that 34 residues from chain $\mathrm{A}$ and 37 residues from chain $\mathrm{B}$ are involved in forming the dimer interface where a total of $2373 \AA^{2}$ is buried between these chains (Lai et al. 2011). The 3PF8 is considered as a dimer interface protein due to (a) the primary hydrophobic interface formed by the $18 / 37$ residues of chain A and chain $B$ (b) the presence of six salt bridges. Total of 54 aminoacid residues Pro131 to $\mathrm{Gln} 184$ are involved in formation of inserted $\alpha / \beta$ subdomain which is arranged in between the $\beta 6$ and $\beta 11$ strands.

The catalytic site of the 3PF8 resembles an open canal in the shape of boomerang ending with a hydrophobic pocket buried in between $\alpha 5$ and $\alpha 6$ of the inserted $\alpha / \beta$ subdomain (Lai et al. 2011). The Ser 106 residue situated in the center of boomerang with two clefts present in the catalytic site is of approximately $13 \AA$ and $7 \AA$ which is large enough for accommodating the acyl groups of the aromatic substrates. The roof of the catalytic site is formed by two protruding hairpins of the inserted $\alpha / \beta$ subdomain, with another cleft of $12 \AA$ accommodating the alkoxyl group of other atoms present on the larger substrates. The catalytic triad of the catalytic site consists of Ser106, His225 and Asp197, where the Ser106 is situated at the nucleophile elbow formed by the $\beta 5$ and $\alpha 4$. The backbone nitrogen atoms of Phe 34 and Gln107 are buried near the base of inserted $\alpha / \beta$ subdomain, which constitutes for the oxyanion hole. The sitedirected mutagenesis experiments conducted on the catalytic triad by Lai et al. (2011) revealed that Ser106, Ala and Asp197, Ala mutants failed to exhibit the catalytic activity; thus, Ser106, His225 and Asp197 constitute for the catalytic function of 3PF8 (Lai et al. 2011). The catalytic site analysis of 3PF8 has revealed that $\alpha / \beta$

Table 4 List of the structural and functional properties of lignin-carbohydrate complex deacetylating esterases belonging to carbohydrate esterases CE1, CE15 classes

\begin{tabular}{|c|c|c|c|c|}
\hline Strain, PDB ID, CE class & Enzyme and fold & $\begin{array}{l}\text { Catalytic residues } \\
\text { and reaction type }\end{array}$ & CATH and Pfam & Substrates and Refs \\
\hline Lactobacillus johnsonii, [3PF8], CE-1 & $\begin{array}{l}\text { Cinnamoyl esterase } \\
\alpha / \beta \text { hydrolases }\end{array}$ & $\begin{array}{l}\text { Ser106, His225, Asp197 } \\
\text { Serine esterase }\end{array}$ & $\begin{array}{l}\text { 3-Layer } \alpha / \beta \text { sandwich } \\
\text { Rossmann fold } \\
\alpha / \beta \text { hydrolase family }\end{array}$ & $\begin{array}{l}\text { Ferulic acid, Caffeic acid and ethyl } \\
\text { ferulate. Cinnamoyl esterase is } \\
\text { active against short acyl chain } \\
\text { aliphatic esters and phenolic esters } \\
\text { (Lai et al. 2011) }\end{array}$ \\
\hline Aspergillus niger, [1UWC], CE-1 & $\begin{array}{l}\text { Feruloyl esterase } \\
\alpha / \beta \text { hydrolases }\end{array}$ & $\begin{array}{l}\text { Ser133, His247, Asp194 } \\
\text { Serine esterase }\end{array}$ & $\begin{array}{l}\text { 3-Layer } \alpha / \beta \text { sandwich } \\
\text { Rossmann fold } \\
\text { Lipase class } 3\end{array}$ & $\begin{array}{l}\text { Arabinoxylans (hydrolysis of feruloyl- } \\
\text { arabinose ester bond) pectin } \\
\text { (feruloyl-galactose ester). High } \\
\text { substrate specificity towards esters } \\
\text { where feruloyl group is attached } \\
\text { to C-5 of arabinose and inactive } \\
\text { against C-2 esters (McAuley et al. } \\
\text { 2004) }\end{array}$ \\
\hline $\begin{array}{l}\text { Sporotrichum thermophile, [4G4J], } \\
\text { CE-15 }\end{array}$ & $\begin{array}{l}\text { Glucuronoyl ester- } \\
\text { ase, } a / \beta \text { hydrolases }\end{array}$ & $\begin{array}{l}\text { Ser213, Glu236, His346 } \\
\text { Serine hydrolase }\end{array}$ & $\begin{array}{l}\text { 3-Layer } \alpha / \beta \text { sandwich } \\
\text { Rossmann fold }\end{array}$ & $\begin{array}{l}\text { It has high specificity for hydrolyzing } \\
\text { the ester bonds of 4-O-methyl- } \\
\text { D-glucuronic acid units of glucu- } \\
\text { ronoxylan and alcohols of lignin } \\
\text { (Charavgi et al. 2013) }\end{array}$ \\
\hline
\end{tabular}


subdomain residues from Pro131 to Gln184 might play a crucial role in substrate binding. Lai et al. (2011) have hypothesized that inserted $\alpha / \beta$ subdomain plays a critical role in holding the phenolic ring of phenolic esters in the appropriate position for the catalytic reaction; however, its role diminishes when aliphatic esters were used as the enzyme substrates. Trp160 residue situated on the second hairpin formed between the $\beta 9$ and $\beta 10$ plays an important role in fixing the substrate as the rotation of Trp 160 forms a tunnel for burying the ferulic acid in the catalytic site. In addition, the side chains of Asp138 and Trp169 are involved in forming hydrogen bonds with the hydroxyl groups of aromatic rings of ferulic acid and caffeic acid in the catalytic pocket of 3PF8. It was reported that substrate orientation in the 3PF8 catalytic site plays a critical role in its catalysis; thus, appropriate orientation by the substrate is acquired through its interactions with the enzyme (aromatic substituents on one end of ligand and ester groups on another end). These interactions cease the carbonyl group at the oxyanion hole, thus allowing the molecule to bend. Contrastingly, the functional groups other than ester groups such as alkoxy groups of ferulic acid/ethyl ferulate, quinic acid group of chlorogenic acid do not exhibit any role in substrate binding (Lai et al. 2011) (Fig. 4).

\section{Aspergillus niger (Feruloyl esterase CE class-I)}

The three-dimensional structure of feruloyl esterase isolated from A. niger was revealed by (McAuley et al. 2004). The protein structure of feruloyl esterase (FAE) contains two FAE-III molecules, two sulfate ions and 399 water molecules. This protein contains the standard $\alpha / \beta$ hydrolase fold with five $\alpha$-helices and two $\beta$-sheets surrounding the central core (nine $\beta$-sheets). FAE-III is glycosylated at Asp79 residue and at every glycosylation site, a $\mathrm{N}$-acetyl glucosamine was observed. The clear and organized electron density maps of FAE-III prove that NAG residues were not attached to any other carbohydrate residues. The catalytic site of the FAE-III contains Ser133, Asp194 and His247; His247 is well organized to form hydrogen bonds with other two residues (Ser133 and Asp194); $\mathrm{N}^{\varepsilon}$ atom forms hydrogen bonds with $\mathrm{O}^{\gamma}$ atom of Ser133; and similarly, $\mathrm{N}^{\delta}$ connects with the Asp194 through hydrogen bonding. This characteristic arrangement of catalytic triad residues denotes that enzymes involved breakdown of amide or ester bonds through nucleophile attack. The serine residue (Ser133) performs nucleophilic attack on the carbonyl atom of the substrate molecule and His247 residue deprotonates Ser133 residue by acting as general base and finally, the positive charge on the His247 is stabilized by the negatively charged Asp194 residue through electrostatic interaction. This catalytic reaction results in

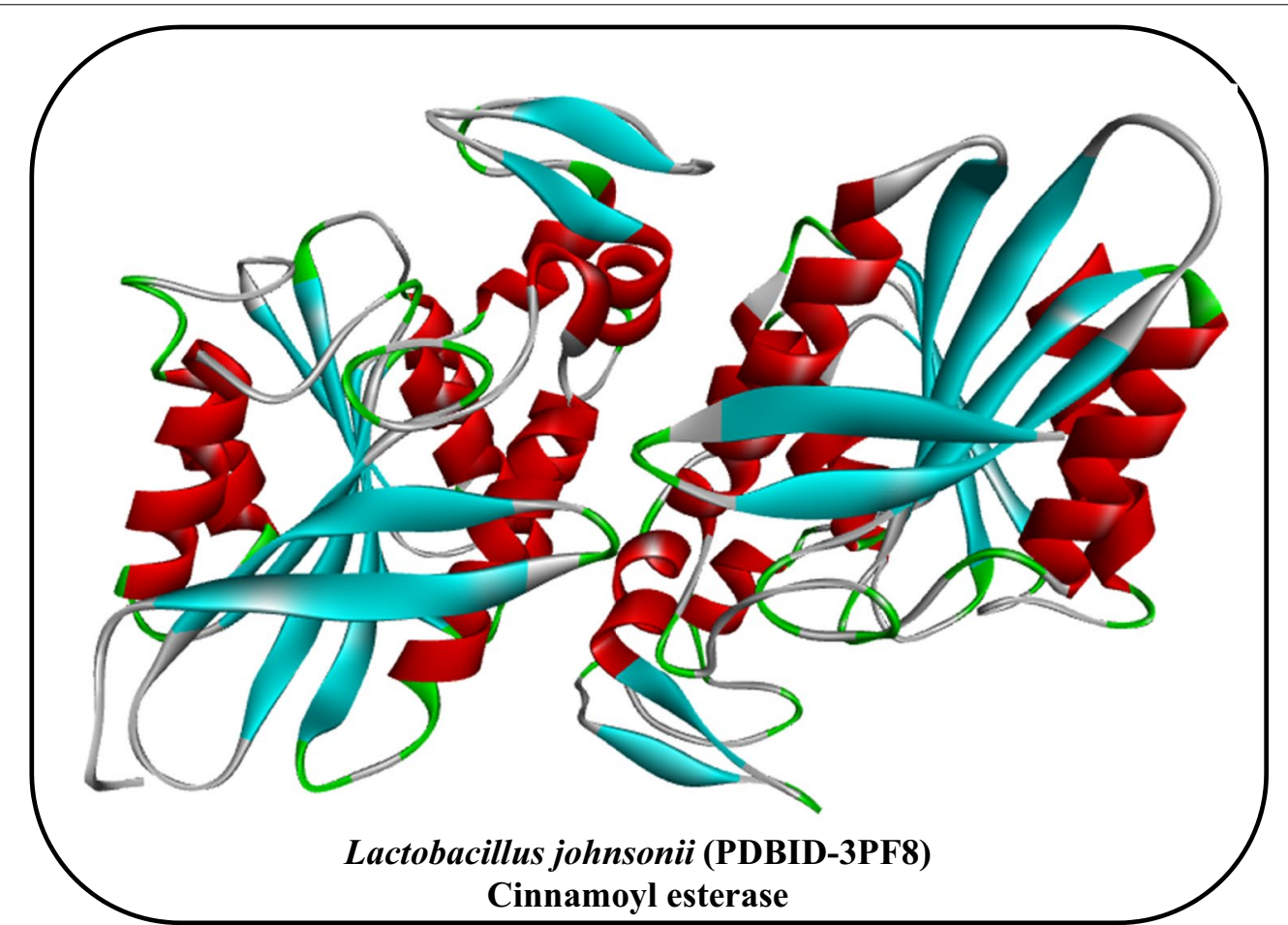

Fig. 4 The protein secondary structure of Lactobacillus johnsonii cinnamoyl esterase (carbohydrate esterase class-I) (PDB ID:3PF8) (Lai et al. 2011), where alpha-helices (red), beta strands (blue) and coils (gray). (Image was developed using Discovery Studio Visualizer ${ }^{\circledR}$ ) 
a tetrahedral transition state which is further collapsed to give an acyl-enzyme intermediate. This intermediate is attacked by the nucleophilic water molecule which was in turn activated by the histidine residue. The second tetrahedral transition intermediate is formed due to the release of acid; the oxyanion formed by the backbone $\mathrm{N}$ atoms of Thr68 and Leu134 residues stabilizes the negative charge on $\mathrm{O}$ atom of carbonyl group present in the tetrahedral transition state.

The two molecules of FAE-III contain the well-organized active site residues having single conformation to the catalytic triad and with the known hydrogen bonding patterns between residues (Hedstrom 2002; McAuley et al. 2004). The tertiary structure of FAE-III is similar to other fungal lipases, as the rmsd values between the FAEIII and RmL (Rhizomucor miehei), FAE-III and TIL (Thermomyces lanuginosa) were $1.0 \AA$ (over $217 \mathrm{C} \alpha$ atoms) and $1.3 \AA$ (over $205 \mathrm{C} \alpha$ atoms). Based on the conformation states, the lipases are classified as active and inactive forms; the catalytic residues are exposed in active form and in inactive forms, these residues are closed by a helical lid. FAE-III residues ranging from 71 to 77 are involved in formation of the helical lid but it does not cover the active site and functions as an active form. According to Aliwan et al. (1999), the occurrence of the helix in two different conformations in FAE-III is questionable as it lacks the lipase activity (Aliwan et al. 1999). Although FAE-III and lipases are similar in their overall structure, difference in their active site regions was expected as they accommodate different substrates. FAEIII contains large number of polar amino acids exposed around the catalytic site, but it is expected that lipases contain hydrophobic residues on its surface. The interaction between ferulic acid and FAE-III happens through $\mathrm{OH}, \mathrm{CH} 3$ side chains and Tyr80 hydroxyl groups. The carboxylate group is situated near the oxyanion hole near the catalytic site serine residue, main chain $\mathrm{N}$ atom (Leu134) and backbone $\mathrm{N}$ and $\mathrm{OH}$ atoms of Thr68. The presence of Leu199 and Ile196 residues provides a hydrophobic environment. McAuley et al. (2004) have reported that residues involved in binding to the ferulic acid were found to be similar in both native and complexed structures of FAE-III. This study has also reported that ferulic acid binds to the proteins in an unproductive way as it contains third molecule of ferulic acid present in the FAE-III complex at approximately $20 \AA$ distance from the catalytic site. Ferulic acid interacts with AsnA223 of molecule A and AspB217 of molecule B of other asymmetric unit through a water molecule (McAuley et al. 2004) (Fig. 5).

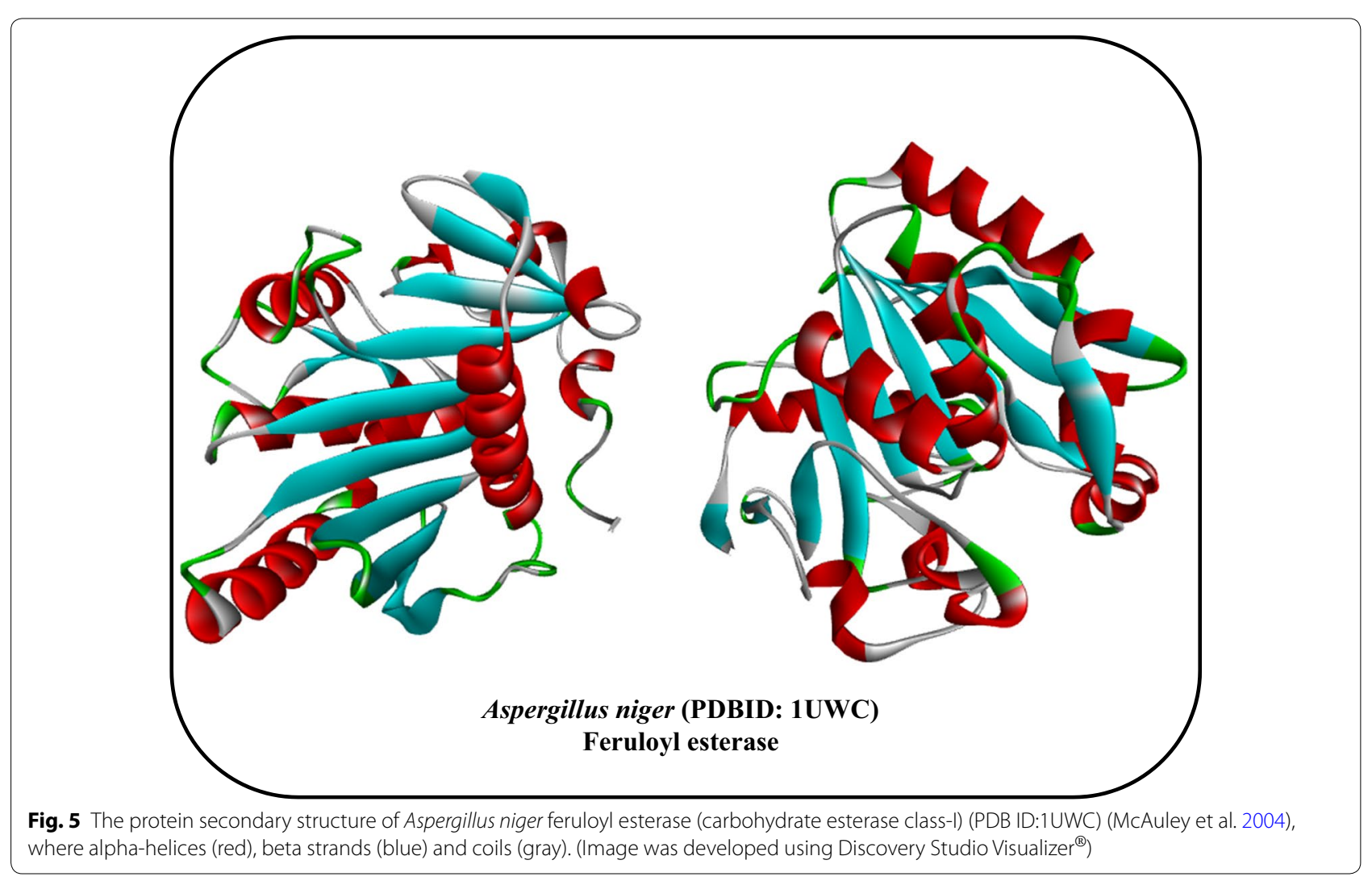




\section{Myceliophthora thermophile (Glucuronoyl esterase)}

Three-dimensional structure of glucuronoyl esterase isolated from Sporotrichum thermophile (StGE2) was explained by (Charavgi et al. 2013). The StGE2 is a serine-type hydrolase family containing a three-layer $\alpha \beta \alpha$ sandwich hydrolase fold with a Rossmann-fold topology (Charavgi et al. 2013). Though StGE2 structure belongs to $\alpha / \beta$ hydrolase superfamily, it deviates from the standard $\alpha / \beta$ hydrolase fold. The $\beta$-sheet of StGE2 is expanded due to the insertion of two antiparallel $\beta$-strands at the $\mathrm{N}$-terminus of StGE2 forming a twisted $\beta$-sheet. This twisted $\beta$-sheet is sandwiched between 18 helices arranged in two layers, eight $\alpha$-helices and $3_{10}$ helices are arranged on one side of the $\beta$-sheet and on the opposite side, another set of eight $\alpha$-helices and $3_{10}$ helices are equally divided. However, the standard $\alpha / \beta$ hydrolase fold exhibits eight strands of $\beta$-sheets in the central core of the structure sandwiched between two clusters of $\alpha$-helices (Charavgi et al. 2013; Ollis et al. 1992) (Fig. 6). The StGE2 structure is stabilized by three disulfide bonds (Cys31-Cys65, Cys212-Cys347 and Cys244-Cys319). The catalytic triad of StGE2 is represented by Ser213, Glu236 and His346, where it deviates from the standard catalytic triad sequence (Ser-Asp-His). The Ser213 situated between the S6 strand and H6 helix (forming a characteristic nucleophilic elbow) performs nucleophilic attack on the substrate, His346 acts as acid/base suggesting the nature of the substrate and Glu236 stabilizes the positive charge of His346. The structural organization and conformation of the catalytic triad are stabilized by the internal hydrogen bonds formed between Ser213 hydroxyl group and NE2 of His346, OE1 of Glu236 and ND1 of His346 (Charavgi et al. 2013). The catalytic triad is also stabilized by the direct and water-mediated polar linkages formed by Arg214, Gly216, Lys217, Gln235, Phe304 and Asn306 residues. Along with these interactions, the disulfide bridges formed by the Cys347 and Cys212 also enhance the rigidity of the catalytic site by bridging Ser 213 and His346 residues. Active site of StGE2 is located on the surface of the molecule and exposed to the solvent molecules and unaffected by other interactions. The site directed mutagenesis experiments of Ser213 residue to understand the structural and functional properties of StGE2 (Charavgi et al. 2013). However, the superposition of StGE2 with the S213A mutant structures on $\mathrm{C}^{\alpha}$ atoms with a rmsd value of $0.4 \AA$ shows that both StGE2 and

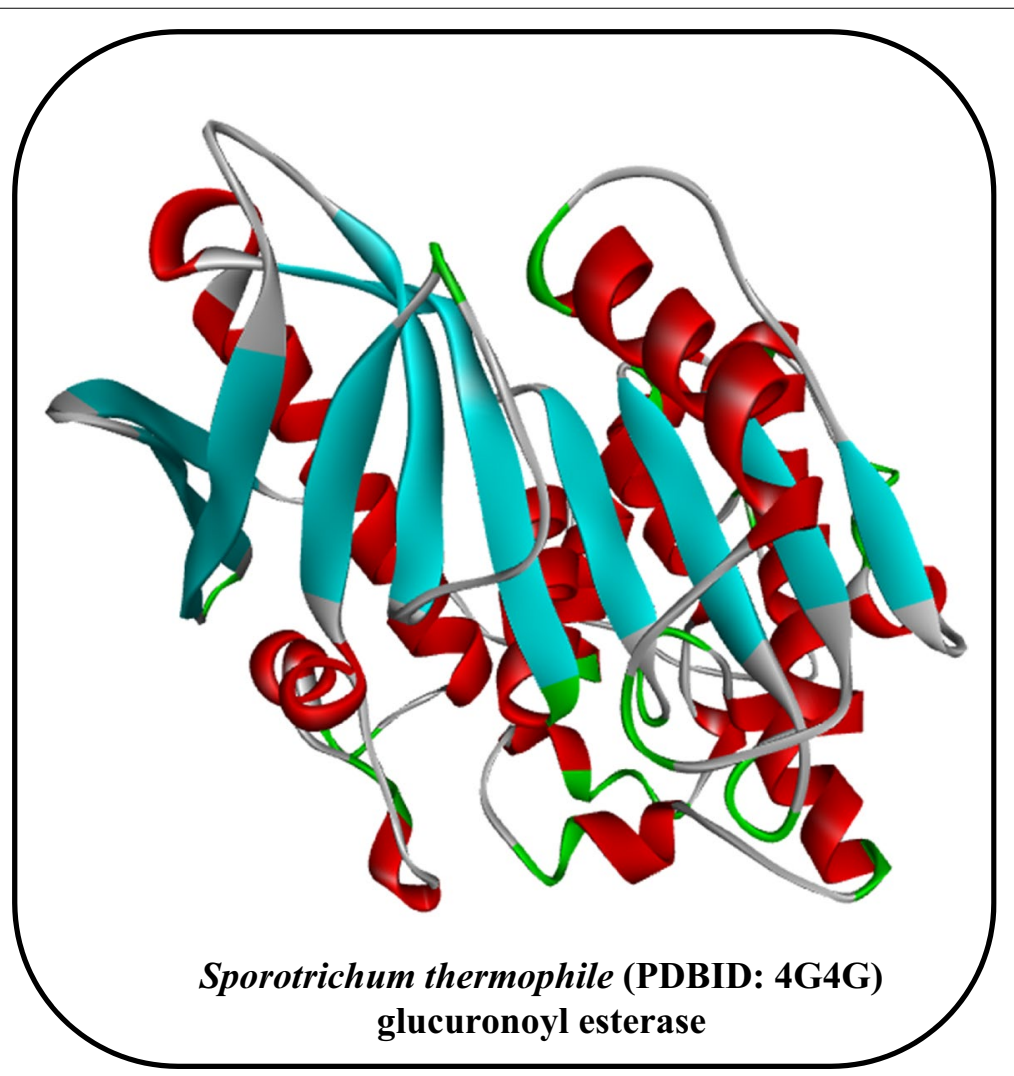

Fig. 6 The protein secondary structure of Sporotrichum thermophile glucuronoyl esterase (carbohydrate esterase class-I) (PDB ID:4G4G) (Charavgi et al. 2013), where alpha-helices (red), beta strands (blue) and coils (gray). (Image was developed using Discovery Studio Visualizer ${ }^{\circledR}$ ) 
S213A mutants differ slightly. Similarly, the superposition of S213A mutant complexed with methyl 4-O-methyl$\beta$-D-glucopyranuronate (MCU) with StGE2 and S213A mutant crystals showed that substrate analog of MCU binds to the active site without disturbing the structure of the protein. The RMSD values obtained from the superposition of S213A mutant bound to MCU with the S213A mutant and StGE2 on $C^{\alpha}$ atoms was $0.40 \AA$ and $0.12 \AA$. The residues present around and in the catalytic triad with surface areas $27.1 \AA^{2}$ (Ser213), $2.7 \AA^{2}$ (Glu236) and $75.7 \AA^{2}$ (His346) are exposed to the solvent. The sitedirected mutagenesis experiment on Ser213 with Ala residue has confirmed that lack of the hydroxyl group did not affect the catalytic site conformation.

The structure analysis of S213A mutant bound with MCU has revealed the catalytic function of the StGE2 protein. The substrate $\mathrm{MCU}$ is bound to the catalytic site residues through seven direct, four indirect and 59 van der Waals interactions (Charavgi et al. 2013). The $\mathrm{MCU}$ analog binds to the cavity through its $\mathrm{O}$ atom of the hydroxyl group present on the glucopyranose ring; the side chains of Gln259 and Glu267 residues of S213A mutant interact with $\mathrm{O} 1, \mathrm{O} 2$ and $\mathrm{O} 3$ of sugar by hydrogen bonding. When compared to the structure of StGE2, the Glu267 side chain residue conformation in S213A mutant differs by dihedral angle of $\sim 74^{\circ}$ supporting the strong binding of the substrate analog, whereas StGE2 Glu267 is arranged at dihedral angle of $\sim 127^{\circ}$. The oxygen groups present on the substrate interact with residues Trp310 NE1 (O2) and Lys217 NZ (O3 and O4) of the protein (Charavgi et al. 2013). Similarly, O6a which relates to the ester bond interacts with NE2 atom present on the imidazole ring of His 346 . The interactions among the $\mathrm{N}$ atom of Arg214 and its side chains with the methoxy group (O4 atom) and ester group (O6 atom) which further forms hydrogen bonds with Ser213 OG suggests that Arg214 is involved in the oxyanion hole formation (Charavgi et al. 2013) (Fig. 6).

\section{Commercial significance of pectin and lignin de-esterases} Commercially, pectin methyl esterases are majorly applied in association with pectinases in food and beverage processing industries. The presence of pectin leads to cloudiness of the fruit juices; pectinase preparations are applied industrially for clarifying and reducing the viscosity of fruit juices and eases the process of concentration and filtration (Demir et al. 2001). Pectinases are applied in combinations with cellulases; hemicellulases were applied for the disruption of plant cell walls and commercially used to produce juices from tropical fruits (Alkorta et al. 1998; Massiot et al. 1997; Wicker et al. 2002). Industrial processes used for preservation of fruits and vegetables such as blanching, washing, freezing, dehydration, sterilization and pasteurization lead to severe physical damage of plant cellular tissues including primary cell wall and middle lamella. However, recently, these traditional methods were replaced with vacuum infusion methods using pectin methyl esterases and calcium chloride mixture to overcome the negative effects of fruits- and vegetables-processing methods (Suutarinen et al. 2000, 2002). Based on its degree of esterification, pectin is divided into low-methoxylated (LM) and high-methoxylated (HM) (Kohli et al. 2015). The HM pectin is generally used for the production of high-sugar jams and jellies. As the HM pectin follows a hydrophobic interaction and dehydration at low $\mathrm{pH}$ for its gelling and to achieve proper gelling of the HM pectin, higher sugar concentrations are essential (Kohli et al. 2015). Contrastingly, LM pectin follows different gelling mechanisms through ionic interactions as it contains calcium (divalent cations) which interacts with the free carboxylic acid groups resulting in a successful cross linkage; therefore, LM pectin does not require higher concentrations of sugar for gelling. Thus, industrially LM pectin is used for the production of low-sugar jellies and jams suitable for the consumption of diabetic patients (Kohli et al. 2015). The apple- and orange-peel wastes are rich in pectin; thus, it is industrially used as gelling and thickening agents. However, the degree of esterification significantly affects the thickening and gelling property of the pectin. Pectin methyl esterases are used for retrieving pectin with lower degree of esterification (Kohli et al. 2015; Morris et al. 2000).

Industrially, feruloyl esterases are applied in various biotechnological processes such as production of platform chemicals, fuel, animal feed, textile, paper and pulp, food processing, agriculture and pharmaceutical industries (Fazary and Ju 2013). In the last few decades, several studies were being conducted to understand and increase the activity of enzymes used in paper and pulp industries. Enzyme mixtures containing feruloyl esterases and acetyl xylan esterases enhance the enzymatic activity of hemicellulases and cellulases, by breaking down the substitutions and linkages between lignin and carbohydrate complexes and solubilize the complex (Fazary and Ju 2013; Mathew and Abraham 2004; Topakas et al. 2004). The lignocellulolytic enzyme mixtures including feruloyl esterases, secreted by fungi, were being applied for the pretreatment of animal feedstock. Pretreatment of animal feedstock with the lignocellulolytic enzyme mixtures were significantly found to increase the activity of rumen microbiota by $80 \%$, thus increasing the rate of digestion (Mathew and Abraham 2004; Tarbouriech et al. 2005; Topakas et al. 2004). Major applications of feruloyl esterases were reported in food and pharmaceutical industries by converting cinnamic acid/ferulic acid and other 
phenolic compounds into commercially valuable products like vanillin (Fazary and Ju 2013). Feruloyl esterases are also applied for improving the quality of bread, preparation and clarification of juices, synthesis of oligosaccharides and production of medicinal compounds (Fazary and Ju 2013). Glucuronoyl esterases are active against a wide range of natural and synthetic lignin-carbohydrate complexes (Hüttner et al. 2017). Specifically, glucuronoyl esterases cleave ester linkages between the lignin and glucuronoxylan complexes (Arnling Bååth et al. 2016). Thus, glucuronoyl esterases share various industrial applications in common with feruloyl esterases. Glucuronoyl esterases are primarily used in biofuel industries in combinations with other lignocellulolytic enzymes for conversion of plant biomass into fuel. Studies have reported that the presence of glucuronoyl esterases in the enzyme mixture has significantly improved the rate of substrate hydrolysis (d'Errico et al. 2016). Glucuronoyl esterases are also applied in food and beverage industries for the clarification and concentration of fruit juices and wine. Glucuronoyl esterases are also applied for synthetically altering glucuronic acid derivatives for developing nonionic surfactants and other bioactive substances with great applications in the pharmaceutical (anti tumorous prodrugs) and cosmetic preparations (De Graaf et al. 2004). Studies were continuously being conducted for developing recombinant plants-vulnerable plant cell-wall components (Lionetti et al. 2010; Sticklen 2006); parallelly, studies were also reported to develop the recombinant enzymes with higher rate of hydrolysis and greater substrate-binding abilities (Himmel et al. 2007; Martinez et al. 2009). In this article, we have listed some of the state-of-the-art articles based on enzyme engineering and developing efficient recombinant enzymes (Bloom et al. 2005; Chen et al. 2018; Dalby 2007; Damborsky and Brezovsky 2014; Gaj et al. 2013; Jørgensen et al. 2007; Martinez et al. 2009; Taylor et al. 2001; Tischer and Wedekind 1999).

\section{Conclusions}

In nature, plant cell-wall components occur in esterified form a type defensive mechanism adapted for inhibiting the activity of enzymes secreted by invading microorganisms. However, these invading microorganisms have evolved over the course of time and developed an efficient enzyme system for the de-esterification of the plant cell-wall components. Pectin methyl esterases, feruloyl/cinnamoyl esterases and glucuronoyl esterases play a significant role in plant biomass conversion by de-esterifying pectin and lignin-carbohydrate complexes and provide an accessible substrate for the acting enzymes secreted by microorganisms. Industrially, these de-esterifying enzymes are highly significant as they are involved in the production of commercially valuable products ranging from food, beverage, textile, pulp and paper, biofuel and pharmaceutical industries. Continuous studies were being conducted to understand and reveal the catalytic mechanisms and to develop an efficient set of de-esterifying enzymes with high rate of substrate hydrolysis. In this article, we have discussed specifically about the structural and functional aspects of pectin (pectin methyl esterase) and lignin-carbohydrate complex (feruloyl/cinnamoyl and glucuronoyl esterases) de-esterifying enzymes. We have extensively conversed by comparing the structures of $E$. chrysanthemi and $A$. aculeatus for pectin esterases, $L$. johnsonii, A. niger for feruloyl/cinnamoyl esterases and $S$. thermophile for glucuronoyl esterase. Understanding the active catalytic residues of these de-esterifying enzymes will significantly help in developing recombinantly active enzymes with higher substrate hydrolysis rates. It is highly necessary to understand the structural and functional properties of plant biomass de-esterifying enzymes, as they stand on first place in bioconversion of plant biomass into commercially valuable products.

\section{Abbreviations \\ CE: carbohydrate esterases; CAZy: carbohydrate active enzymes; PDB: protein data bank; PME: pectin methyl esterase; FAE: ferulic acid esterases (or) feruloyl esterases; CAE: cinnamic acid esterase (or) cinnamoyl esterase; StGE2: Sporotri- chum thermophile glucuronoyl esterase 2; HM: highly methoxylated; LM: low methoxylated.}

\section{Authors' contributions}

AKS is a Ph.D. research fellow wrote the manuscript. WQ was the principal supervisor who supervised in writing the manuscript and provided comments and revisions to the manuscript. Both authors read and approved the final manuscript.

\section{Acknowledgements}

Not applicable.

Competing interests

The authors declare that they have no competing interests.

\section{Availability of data and materials}

The data presented and supporting the conclusion of our manuscript were mostly presented in the form of text; structural images and functional properties were previously reported and published. The PDB IDs and structural and functional properties reported in our manuscript were cited in the manuscript.

\section{Consent for publication}

Not applicable.

Ethics approval and consent to participate Not applicable.

Funding

This work was supported by Natural Sciences and Engineering Research Council of Canada Funding (RGPIN-2017-05366) to Wensheng Qin and Ontario Trillium Scholarship (OTS) to Ayyappa Kumar Sista Kameshwar. 


\section{Publisher's Note}

Springer Nature remains neutral with regard to jurisdictional claims in published maps and institutional affiliations.

Received: 7 August 2018 Accepted: 3 October 2018

Published online: 10 October 2018

\section{References}

Albersheim P, Killias U (1963) Histochemical localization at the electron microscope level. Am J Bot 50:732-745

Aliwan FO, Kroon PA, Faulds CB, Pickersgill R, Williamson G (1999) Ferulic acid esterase-III from Aspergillus niger does not exhibit lipase activity. J Sci Food Agric 79:457-459

Alkorta I, Garbisu C, Llama MJ, Serra JL (1998) Industrial applications of pectic enzymes: a review. Process Biochem 33:21-28

Arnling Bååth J, Giummarella N, Klaubauf S, Lawoko M, Olsson L (2016) A glucuronoyl esterase from Acremonium alcalophilum cleaves native lignin-carbohydrate ester bonds. FEBS Lett 590:2611-2618

Benoit I et al (2006) Feruloyl esterases as a tool for the release of phenolic compounds from agro-industrial by-products. Carbohydr Res 341:1820-1827

Benoit I, Danchin EG, Bleichrodt R-J, de Vries RP (2008) Biotechnological applications and potential of fungal feruloyl esterases based on prevalence, classification and biochemical diversity. Biotechnol Lett 30:387-396

Bloom JD, Meyer MM, Meinhold P, Otey CR, MacMillan D, Arnold FH (2005) Evolving strategies for enzyme engineering. Curr Opin Struct Biol 15:447-452

Charavgi M-D, Dimarogona M, Topakas E, Christakopoulos P, Chrysina ED (2013) The structure of a novel glucuronoyl esterase from Myceliophthora thermophila gives new insights into its role as a potential biocatalyst. Acta Crystallogr D Biol Crystallogr 69:63-73

Chen X, Li W, Ji P, Zhao Y, Hua C, Han C (2018) Engineering the conserved and noncatalytic residues of a thermostable $\beta$-1, 4-endoglucanase to improve specific activity and thermostability. Sci Rep 8:2954

Cosgrove DJ (1997) Assembly and enlargement of the primary cell wall in plants. Annu Rev Cell Dev Biol 13:171-201

Dalby PA (2007) Engineering enzymes for biocatalysis. Recent Patents Biotechnol 1:1-9

Damborsky J, Brezovsky J (2014) Computational tools for designing and engineering enzymes. Curr Opin Chem Biol 19:8-16

De Graaf M, Nevalainen TJ, Scheeren HW, Pinedo HM, Haisma HJ, Boven E (2004) A methylester of the glucuronide prodrug DOX-GA3 for improvement of tumor-selective chemotherapy. Biochem Pharmacol 68:2273-2281

De Lorenzo G, Salvi G, Degra L, D'ovidio R, Cervone F (1987) Induction of extracellular polygalacturonase and its mRNA in the phytopathogenic fungus Fusarium moniliforme. Microbiology 133:3365-3373

Del Río JC, Marques G, Rencoret J, Martínez ÁT, Gutiérrez A (2007) Occurrence of naturally acetylated lignin units. J Agric Food Chem 55:5461-5468

Demir N, Acar J, Sarıoğlu K, Mutlu M (2001) The use of commercial pectinase in fruit juice industry. Part 3: immobilized pectinase for mash treatment. J Food Eng 47:275-280

Derewenda ZS, Derewenda U (1991) Relationships among serine hydrolases: evidence for a common structural motif in triacylglyceride lipases and esterases. Biochem Cell Biol 69:842-851

d'Errico C, Börjesson J, Ding H, Krogh KB, Spodsberg N, Madsen R, Monrad RN (2016) Improved biomass degradation using fungal glucuronoyl-esterases-hydrolysis of natural corn fiber substrate. J Biotechnol 219:117-123

Ďuranová M, Hirsch J, Kolenova K, Biely P (2009) Fungal glucuronoyl esterases and substrate uronic acid recognition. Biosci Biotechnol Biochem 73:2483-2487

Faulds CB (2010) What can feruloyl esterases do for us? Phytochem Rev 9:121-132

Faulds CB, Zanichelli D, Crepin VF, Connerton IF, Juge N, Bhat MK, Waldron KW (2003) Specificity of feruloyl esterases for water-extractable and water-unextractable feruloylated polysaccharides: influence of xylanase. J Cereal Sci 38:281-288

Faulds C, Mandalari G, Curto RL, Bisignano G, Christakopoulos P, Waldron K (2006) Synergy between xylanases from glycoside hydrolase family 10 and family 11 and a feruloyl esterase in the release of phenolic acids from cereal arabinoxylan. Appl Microbiol Biotechnol 71:622-629

Fazary AE, JU YH (2007) Feruloyl esterases as biotechnological tools: current and future perspectives. Acta Biochim Biophys $\operatorname{Sin} 39: 811-828$

Fazary AE, Ju Y-H (2013) The large-scale use of feruloyl esterases in industry. Biotechnol Mol Biol Rev 3:95-110

Förster H (1988) Pectinesterases from Phytophthora infestans. In: Wood WA, Kellogg ST (eds) Methods in enzymology, vol 161. Academic Press, pp 355-361

Fries M, Ihrig J, Brocklehurst K, Shevchik VE, Pickersgill RW (2007) Molecular basis of the activity of the phytopathogen pectin methylesterase. EMBO J 26:3879-3887

Fu J-T, Rao M (1999) The influence of sucrose and sorbitol on gel-sol transition of low-methoxyl pecti+ Ca 2+ gels. Food Hydrocolloids 13:371-380

Fu J, Rao M (2001) Rheology and structure development during gelation of low-methoxyl pectin gels: the effect of sucrose. Food Hydrocolloids 15:93-100

Gaj T, Gersbach CA, Barbas CF III (2013) ZFN, TALEN, and CRISPR/Cas-based methods for genome engineering. Trends Biotechnol. 31:397-405

Garcića Maceira FI, Di Pietro A, Roncero MIG (1997) Purification and characterization of a novel exopolygalacturonase from Fusarium oxysporum f. sp. lycopersici. FEMS Microbiol Lett 154:37-43

Gee M, Reeve R, McCready R (1959) Reaction of hydroxylamine with pectinic acids. Chemical studies and histochemical estimation of the degree of esterification of pectic substances in fruit. J Agric Food Chem 7:34-38

Gonzalez SL, Rosso ND (2011) Determination of pectin methylesterase activity in commercial pectinases and study of the inactivation kinetics through two potentiometric procedures. Food Sci Technol (Campinas) 31:412-417

Guglielmetti S, De Noni I, Caracciolo F, Molinari F, Parini C, Mora D (2008) Bacterial cinnamoyl esterase activity screening for the production of a novel functional food product. Appl Environ Microbiol 74:1284-1288

Hedstrom L (2002) Serine protease mechanism and specificity. Chem Rev 102:4501-4524

Himmel ME, Ding S-Y, Johnson DK, Adney WS, Nimlos MR, Brady JW, Foust TD (2007) Biomass recalcitrance: engineering plants and enzymes for biofuels production. Science 315:804-807

Hüttner S, Klaubauf S, de Vries RP, Olsson L (2017) Characterisation of three fungal glucuronoyl esterases on glucuronic acid ester model compounds. Appl Microbiol Biotechnol 101:5301-5311

Ishii T (1997) O-acetylated oligosaccharides from pectins of potato tuber cell walls. Plant Physiol 113:1265-1272

Jayani RS, Saxena S, Gupta R (2005) Microbial pectinolytic enzymes: a review. Process Biochem 40:2931-2944

Jenkins J, Mayans O, Smith D, Worboys K, Pickersgill RW (2001) Three-dimensional structure of Erwinia chrysanthemi pectin methylesterase reveals a novel esterase active site. J Mol Biol 305:951-960

Johansson K, El-Ahmad M, Friemann R, Jörnvall H, Markovič O, Eklund H (2002) Crystal structure of plant pectin methylesterase. FEBS Lett 514:243-249

Jørgensen H, Kristensen JB, Felby C (2007) Enzymatic conversion of lignocellulose into fermentable sugars: challenges and opportunities. Biofuels Bioprod Biorefin 1:119-134

Kashyap D, Vohra P, Chopra S, Tewari R (2001) Applications of pectinases in the commercial sector: a review. Bioresour Technol 77:215-227

Kobayashi T, Higaki N, Yajima N, Suzumatsu A, Hagihara H, Kawai S, Ito S (2001) Purification and properties of a galacturonic acid-releasing exopolygalacturonase from a strain of Bacillus. Biosci Biotechnol Biochem 65:842-847

Kohli P, Kalia M, Gupta R (2015) Pectin methylesterases: A review. J Bioprocess Biotech 5:1

Kroon PA, Faulds CB, Ryden P, Robertson JA, Williamson G (1997) Release of covalently bound ferulic acid from fiber in the human colon. J Agric Food Chem 45:661-667

Lai K-K et al (2011) An inserted a/ $\beta$ subdomain shapes the catalytic pocket of Lactobacillus johnsonii cinnamoyl esterase. PLOS ONE 6:e23269

Laszlo JA, Compton DL, Li X-L (2006) Feruloyl esterase hydrolysis and recovery of ferulic acid from jojoba meal. Ind Crops Prod 23:46-53

Lionetti $\vee$ et al (2010) Engineering the cell wall by reducing de-methyl-esterified homogalacturonan improves saccharification of plant tissues for bioconversion. Proc Natl Acad Sci 107:616-621

Luh B, Phaff H (1951) Studies on polygalacturonase of certain yeasts. Arch Biochem Biophys 33:212-227 
Manachini P, Fortina M, Parini C (1987) Purification and properties of an endopolygalacturonase produced by Rhizopus stolonifer. Biotechnol Lett 9:219-224

Marcus L, Barash I, Sneh B, Koltin Y, Finkler A (1986) Purification and characterization of pectolytic enzymes produced by virulent and hypovirulent isolates of Rhizoctonia solani Kuhn. Physiol Mol Plant Pathol 29:325-336

Maria de Lourdes T, Jorge JA, Terenzi HF (1991) Pectinase production by Neurospora crassa: purification and biochemical characterization of extracellular polygalacturonase activity. Microbiology 137:1815-1823

Martinez AT, Ruiz-Duenas FJ, Martínez MJ, del Rio JC, Gutierrez A (2009) Enzymatic delignification of plant cell wall: from nature to mill. Curr Opin Biotechnol 20:348-357

Massiot P, Perron V, Baron A, Drilleau J-F (1997) Release of methanol and depolymerization of highly methyl esterified apple pectin with an endopolygalacturonase from Aspergillus niger and pectin methylesterases from A. niger or from orange. LWT Food Sci Technol 30:697-702

Mathew S, Abraham TE (2004) Ferulic acid: an antioxidant found naturally in plant cell walls and feruloyl esterases involved in its release and their applications. Crit Rev Biotechnol 24:59-83

McAuley KE, Svendsen A, Patkar SA, Wilson KS (2004) Structure of a feruloyl esterase from Aspergillus niger. Acta Crystallogr D Biol Crystallogr 60:878-887

McCready R, Reeve R (1955) Plant tissue analysis, test for pectin based on reaction of hydroxamic acids with ferric ion. J Agric Food Chem 3:260-262

Micheli F (2001) Pectin methylesterases: cell wall enzymes with important roles in plant physiology. Trends Plant Sci 6:414-419

Mølgaard A, Kauppinen S, Larsen S (2000) Rhamnogalacturonan acetylesterase elucidates the structure and function of a new family of hydrolases. Structure 8:373-383

Morris G, Foster T, Harding S (2000) The effect of the degree of esterification on the hydrodynamic properties of citrus pectin. Food Hydrocolloids 14:227-235

Navarro-Fernández J, Martínez-Martínez I, Montoro-García S, García-Carmona F, Takami H, Sánchez-Ferrer Á (2008) Characterization of a new rhamnogalacturonan acetyl esterase from Bacillus halodurans C -125 with a new putative carbohydrate binding domain. J Bacteriol 190:1375-1382

Nozaki K, Miyairi K, Hozumi S, Fukui Y, Okuno T (1997) Novel exopolygalacturonases produced by Alternaria mali. Biosci Biotechnol Biochem 61:75-80

Ollis DL et al (1992) The $\alpha / \beta$ hydrolase fold. Protein Eng 5:197-211

Pawar PM-A, Koutaniemi S, Tenkanen M, Mellerowicz EJ (2013) Acetylation of woody lignocellulose: significance and regulation. Front Plant Sci 4:118

Pérez S, Rodriguez-Carvajal M, Doco T (2003) A complex plant cell wall polysaccharide: rhamnogalacturonan II. A structure in quest of a function. Biochimie 85:109-121

Pitkänen K, Heikinheimo R, Pakkanen R (1992) Purification and characterization of Erwinia chrysanthemi B374 pectin methylesterase produced by Bacillus subtilis. Enzyme Microb Technol 14:832-836

Pokkuluri PR, Duke NE, Wood SJ, Cotta MA, Li XL, Biely P, Schiffer M (2011) Structure of the catalytic domain of glucuronoyl esterase Cip2 from Hypocrea jecorina. Proteins Struct Funct Bioinform 79:2588-2592

Prade RA, Zhan D, Ayoubi P, Mort AJ (1999) Pectins, pectinases and plantmicrobe interactions. Biotechnol Genet Eng Rev 16:361-392

Record E et al (2003) Overproduction of the Aspergillus niger feruloyl esterase for pulp bleaching application. Appl Microbiol Biotechnol 62:349-355

Reymond P, Deléage G, Rascle C, Fèvre M (1994) Cloning and sequence analysis of a polygalacturonase-encoding gene from the phytopathogenic fungus Sclerotinia sclerotiorum. Gene 146:233-237

Rodriguez-Palenzuela P, Burr T, Collmer A (1991) Polygalacturonase is a virulence factor in Agrobacterium tumefaciens biovar 3. J Bacteriol 173:6547-6552

Sakai T, Okushima M (1982) Purification and crystallization of a protopectinsolubilizing enzyme from Trichosporon penicillatum. Agric Biol Chem 46:667-676

Sakai T, Okushima M, Yoshitake S (1984) Purification, crystallization and some properties of endo-polygalacturonase from Kluyveromyces fragilis. Agric Biol Chem 48:1951-1961

Sakai T, Sakamoto T, Hallaert J, Vandamme EJ (1993) Pectin, pectinase, and protopectinase: production, properties, and applications. In: Laskin Al Neidleman S (eds) Advances in applied microbiology, vol 39. Elsevier, New Jersey, pp 213-294
Sakamoto T, Hours RA, Sakai T (1994) Purification, characterization, and production of two pectic transeliminases with protopectinase activity from Bacillus subtilis. Biosci Biotechnol Biochem 58:353-358

Schrag JD, Cygler M (1997) [4] Lipases and aß hydrolase fold. Methods Enzymol 284:85-107

Selig MJ, Knoshaug EP, Adney WS, Himmel ME, Decker SR (2008) Synergistic enhancement of cellobiohydrolase performance on pretreated corn stover by addition of xylanase and esterase activities. Bioresour Technol 99:4997-5005

Sénéchal F, Wattier C, Rustérucci C, Pelloux J (2014) Homogalacturonanmodifying enzymes: structure, expression, and roles in plants. J Exp Bot 65:5125-5160

Špániková S, Biely P (2006) Glucuronoyl esterase-novel carbohydrate esterase produced by Schizophyllum commune. FEBS Lett 580:4597-4601

Sterling C (1970) Crystal-structure of ruthenium red and stereochemistry of its pectic stain. Am J Bot 57:172-175

Sticklen M (2006) Plant genetic engineering to improve biomass characteristics for biofuels. Curr Opin Biotechnol 17:315-319

Suutarinen J, Honkapää K, Heiniö R, Autio K, Mokkila M (2000) The effect of different prefreezing treatments on the structure of strawberries before and after jam making. LWT Food Sci Technol 33:188-201

Suutarinen J et al (2002) Effects of calcium chloride-based prefreezing treatments on the quality factors of strawberry jams. J Food Sci 67:884-894

Tabka M, Herpoël-Gimbert I, Monod F, Asther M, Sigoillot J (2006) Enzymatic saccharification of wheat straw for bioethanol production by a combined cellulase xylanase and feruloyl esterase treatment. Enzyme Microb Technol 39:897-902

Tapin S, Sigoillot J-C, Asther M, Petit-Conil M (2006) Feruloyl esterase utilization for simultaneous processing of nonwood plants into phenolic compounds and pulp fibers. J Agric Food Chem 54:3697-3703

Tarbouriech N, Prates JA, Fontes CM, Davies GJ (2005) Molecular determinants of substrate specificity in the feruloyl esterase module of xylanase 10B from Clostridium thermocellum. Acta Crystallogr D Biol Crystallogr 61:194-197

Taylor SV, Kast P, Hilvert D (2001) Investigating and engineering enzymes by genetic selection. Angew Chem Int Ed 40:3310-3335

Tierny Y, Bechet M, Joncquiert JC, Dubourguier HC, Guillaume JB (1994) Molecular cloning and expression in Escherichia coli of genes encoding pectate lyase and pectin methylesterase activities from Bacteroides thetaiotaomicron. J Appl Microbiol 76:592-602

Tischer W, Wedekind F (1999) Immobilized enzymes: methods and applications. In: Fessner WD (ed) Biocatalysis-from discovery to application. Springer, New York, pp 95-126

Topakas E, Stamatis H, Biely P, Christakopoulos P (2004) Purification and characterization of a type $B$ feruloyl esterase (StFAE-A) from the thermophilic fungus Sporotrichum thermophile. Appl Microbiol Biotechnol 63:686-690

Topakas E, Vafiadi C, Christakopoulos P (2007) Microbial production, characterization and applications of feruloyl esterases. Process Biochem 42:497-509

Topakas E, Moukouli M, Dimarogona M, Vafiadi C, Christakopoulos P (2010) Functional expression of a thermophilic glucuronoyl esterase from Sporotrichum thermophile: identification of the nucleophilic serine. Appl Microbiol Biotechnol 87:1765-1772

Vierhuis E, Korver M, Schols HA, Voragen AG (2003) Structural characteristics of pectic polysaccharides from olive fruit (Olea europaea cv moraiolo) in relation to processing for oil extraction. Carbohydr Polym 51:135-148

Voragen AG, Coenen G-J, Verhoef RP, Schols HA (2009) Pectin, a versatile polysaccharide present in plant cell walls. Struct Chem 20:263

Whitaker JR (1984) Pectic substances, pectic enzymes and haze formation in fruit juices. Enzyme Microb Technol 6:341-349

Whitaker JR (1990) Microbial pectolytic enzymes. In: Fogarty WM, Kelly CT (eds) Microbial enzymes and biotechnology. Springer, Dordrecht, pp 133-176

Wicker L, Ackerley J, Corredig M (2002) Clarification of juice by thermolabile valencia pectinmethylesterase is accelerated by cations. J Agric Food Chem 50:4091-4095

Yapo BM (2011) Rhamnogalacturonan-l: a structurally puzzling and functionally versatile polysaccharide from plant cell walls and mucilages. Polym Rev 51:391-413 